\title{
Should Guidelines for Conventional Hemodialysis Initiation in Acute Meth- anol Poisoning, Be Revised, When no Fomepizloe is Used?
}

\author{
Reza Hekmat ${ }^{1^{*}}$, Fariboorz Samini ${ }^{1}$, Bita Dadpour ${ }^{1}$, Faezeh Maghsudloo ${ }^{1}$, Mohammad Ja- \\ vad Mojahedi ${ }^{1}$ \\ ${ }^{1}$ Department of Nephrology, Ghaem Hospital, Mashhad, Iran \\ * Corresponding author: Reza Hekmat, Department of Nephrology, Ghaem Hospital, Mashhad, Iran. Tel.: +98-5118012829, Fax: +98-5118409693, E-mail: drhek- \\ matreza@yahoo.com
}

\begin{abstract}
A B S T R A C T
Background: Consumption of home-distilled alcohol may lead to epidemic or sporadic cases of severe acute methanol poisoning. The difficulty of establishing strict indications for hemodialysis in acute methanol poisoning is a widely recognized issue.

Materials and Methods: The determination of the clinical, especially hemodialysis, and para clinical factors influencing patient survival in 46 acutely methanol poisoned patients was the aim of this cross sectional retrospective study. Clinical and paraclinical variables compared in surviving and non-surviving patients were hemodialysis and ventilation requirements, the level of consciousness, ABG parameters the serum methanol, creatinine and BUN levels. Only ethanol was used for ADH (Alcohol Dehydrogenize) blockade.

Results: Receiver operative curve characteristics showed that a serum methanol threshold level of $15 \mathrm{mg} / \mathrm{dl}$, instead of $25 \mathrm{mg} / \mathrm{dl}$, has a better sensitivity and rather the same specificity for predicting patient mortality.

Conclusions: With no fomepizloe and using conventional hemodialysis, lowering the threshold of methanol concentration for hemodialysis initiation, may save lives in acute methanol intoxication.
\end{abstract}

Keywords: Hemodialysis; Methanol; Poisoning

\section{Introduction}

Consumption of home -distilled alcohol may lead to epidemic or sporadic cases of severe acute methanol poisoning. Significant morbidity and mortality in acute methanol intoxication can be prevented by early diagnosis and treatment (1). While some authors suggest that pre-emptive high flux HD (hemodialysis), be performed in severe methanol poisoning (2), others have claimed that even no hemodialysis may be an option in selected cases, especially when using fomepizole (3), physicians experience or preference has also been mentioned as a criteria for dialysis (4). Even the American Academy of Clinical Toxicology's practice guidelines are ambiguous with respect to threshold methanol concentration for hemodialysis (5). However, the American Academy of Clini- cal Toxicology's practice guidelines suggest that, until more work is done, a methanol concentration of $25 \mathrm{mg} /$ dL remains a reasonable indication for hemodialysis (6). Even according to toxicology textbooks, it is difficult to establish strict indications for hemodialysis in methanol poisoning (7).

\section{Materials and Methods}

Forty six acutely methanol poisoned patients between September 2009 and December 2010 serially entered this cross sectional retrospective study at Imam Reza Hospital, Mashhad, Iran. All patients were hemodialyzed using polysulfane filters and bicarbonate buffer. Patients with severe metabolic acidosis (Ph less than 7.20 refractory to bicarbonate therapy), signs of end organ toxicity (includ-

-Article type: Brief Report; Received: 09 Nov 2011, Revised: 21 Apr 2012, Accepted: 12 May 2012; DOI: 10.5812/ircmj.3467

Implication for health policy/practice/research/medical education:

This study discusses about conventional hemodialysis initiation in acute methanol poisoning.

-Please cite this paper as:

Hekmat R, Samini F, Dadpour B, Maghsudloo F, Mojahedi MJ. Should Guidelines for Conventional Hemodialysis Initiation in Acute Methanol Poisoning, Be Revised, when no Fomepizloe is used? Iran Red Cres Med J.2012;14(11):743-5. DOI:10.5812/ircmj.3467

Copyright (C) 2012, Iranian Red Crescent Medical Journal; Published by Kowsar Corp.

This is an Open Access article distributed under the terms of the Creative Commons Attribution License (http://creativecommons.org/licenses/by/3.0), which permits unrestricted use, distribution, and reproduction in any medium, provided the original work is properly cited. 
ing coma and seizures), a methanol toxic level of more than $25 \mathrm{mg} / \mathrm{dl}$ and renal failure (a threefold increase in the serum creatinine or GFR decrease by 75 percent or urine output of $<0.5 \mathrm{~mL} / \mathrm{kg}$ per hour for 24 hours or anuria for 12 hours) were selected for hemodialysis initiation.4-6 Gas chromatography method was used for measuring the methanol's serum level.

ADH (Alcohol Dehydrogenize) blockade other than ethanol administration $(0.8 \mathrm{~g} / \mathrm{kg}$ loading, then $0.8 \mathrm{~g} / \mathrm{kg} /$ hr until urine methanol positivity), due to unavailability of fomepizole, was not provided. Over all 10 patients in both groups (survived and non-survived) had received hemodialysis.

Independent sample t test and Mann Whitney test were used to compare parameters; serum methanol level, blood $\mathrm{PH}$, blood Co2 pressure and blood bicarbonate level in hemodialyzed, non-hemodialyzed and surviving, non-surviving patients. Regression analysis was used to evaluate the effect of clinical and laboratory parameters on patient survival. The receiver operative curve (ROC) procedure was used to evaluate the specificity and sensitivity of different levels of methanol for predicting patien survival. SPSS package version 15 , for statistical analysis, was used. A p-vlue of less than 0.05was considered significant.

\section{Results}

All four cases of mortality had occurred in hemodialyzed patients. The serum methanol level ( Table1), hemodialysis requirement and mechanical ventilation requirement was higher and level of consciousness, was less in non- surviving patients compared to surviving ones.

Table 1. Initial serum methanol level, blood PH, blood Co2 pressure and blood bicarbonate level in hemodialyzed, non-hemodialyzed patients and surviving and non-surviving patients.

\begin{tabular}{|c|c|c|c|c|c|c|}
\hline \multirow[t]{2}{*}{ Factors } & \multicolumn{3}{|c|}{ Hemodialysis status } & \multicolumn{3}{|c|}{ Survival status } \\
\hline & $\begin{array}{l}\text { Hemodialyzed } \\
\text { Mean } \pm \text { SD }\end{array}$ & $\begin{array}{l}\text { Non-hemodi- } \\
\text { alyzed Mean } \\
\pm \text { SD }\end{array}$ & P-value & $\begin{array}{l}\text { Survived } \\
\text { Mean+|-Std. }\end{array}$ & $\begin{array}{l}\text { Non-survived } \\
\text { Mean } \pm \text { SD }\end{array}$ & P-value \\
\hline $\begin{array}{l}\text { Initial serum } \\
\text { methanol level } \\
(\mathrm{mg} / \mathrm{dl})\end{array}$ & $36.30+\mid-33.34$ & $8.79+\mid-2.68$ & 0.001 & $15.53+\mid-21.95$ & $21.75+\mid-15.19$ & 0.048 \\
\hline $\begin{array}{l}\text { Initial blood } \\
\text { PH }\end{array}$ & $7.20+\mid-0.22$ & $7.32+\mid-0.10$ & 0.03 & $7.31+\mid-0.11$ & $7.18+\mid-0.31$ & 0.11 \\
\hline $\begin{array}{l}\text { Initial blood } \\
\text { Co2 pressure ( } \\
\text { mm Hg) }\end{array}$ & $32.02+\mid-12.99$ & $41.10+\mid-10.5$ & 0.054 & $38.76+\mid-12.07$ & 36.76 & 0.78 \\
\hline $\begin{array}{l}\text { Initial blood } \\
\text { bi ca rbo na te } \\
\text { level (m Eq/lit) }\end{array}$ & $13.07+\mid-6.90$ & $21.74+\mid-5.65$ & 0.01 & $20.68+\mid-6.81$ & $15.26+\mid-8.00$ & 0.21 \\
\hline $\begin{array}{l}\text { Initial blood } \\
\text { urea nitrogen } \\
(\mathrm{mg} / \mathrm{dl})\end{array}$ & $20.50+\mid-7.00$ & $16.61+\mid-6.95$ & 0.21 & $16.82+\mid-6.67$ & 23.5 & 0.19 \\
\hline $\begin{array}{l}\text { Initial serum } \\
\text { creat i n i n e } \\
(\mathrm{mg} / \mathrm{dl})\end{array}$ & $1.45+\mid-0.59$ & $1.30+\mid-0.71$ & 0.28 & $1.30+\mid-0.66$ & $1.5+\mid-0.42$ & 0.68 \\
\hline
\end{tabular}

There was no difference regarding the sex, age, body weight and height between the patients who survived and those who died $(\mathrm{P}>0.05)$. The mortality rate was 4 (11\%). General linear model analysis showed the serum methanol level and hemodialysis requirement as the sole determinants of the patient survival in acute methanol poisoning.

None of the deaths in hemodialyzed patients could be attributed to hemodialysis per se, including catheter insertion complications, cardiac arrhythmia or ion derangements occurring during or immediately after hemodialysis. However the mean duration of hemodialysis in both groups was less than 3 hours (mean $\pm \mathrm{SD}=2.61+$ 0.78 ), although the prescribed duration of hemodialysis for both groups was a minimum of 3 hours. The discrep- ancy between prescribed and delivered hemodialysis was due to hemodynamic instability during hemodialysis .Hemodynamic instability during different sessions of hemodialysis occurred in both surviving and non-surviving patients by not a different incidence ratio (chi-square $\mathrm{P}=0.44$ ). Using receiver operative curves characteristics for finding the threshold of serum methanol concentration , separating surviving from non-surviving patients we found that, the serum methanol threshold level of $25 \mathrm{mg} / \mathrm{dl}$, used for initiating hemodialysis, was nearly $100 \%$ specific, but only $33 \%$ sensitive for predicting mortality. But selecting a serum methanol threshold level of $15 \mathrm{mg} / \mathrm{dl}$, instead of more than $25 \mathrm{mg} / \mathrm{dl}$, had a significant improving effect on the sensitivity of the mortality prediction, increasing it to $75 \%$ while not decreasing the 
specificity that continued to remain still at $88 \%$.

\section{Discussion}

Non- realization of methanol i.v dose augmentation (150\% in the protocol used) during hemodialysis also, the lag of time between the presentation and the beginning of hemodialysis cannot explain the non-survival of the demised patients. Then the other explanation may be that conventional hemodialysis with a short duration time (the mean duration time of the effective hemodialysis in our study was less than 3 hours) may be ineffective or initiated too late for salvaging the patients with severe methanol poisoning, especially when no ADH blockade, other than ethanol is used. The lack of CRRT (continuous renal replacement therapy) facilities may have aggravated this.

Others have also suggested that indications and triage for hemodialysis in methanol poisonings should be modified. A longer duration of hemodialysis to bring the serum methanol levels down to a nontoxic level (811), pre-emptive hemodialysis with high-flux membranes (2) or immediate (12) hemodialysis were the options forwarded for this modification. Ghannoum M et al. (9) emphasized that hemodialysis should be considered for all cases of sever methanol intoxication, even when metabolic acidosis is absent, since methanol itself, contributes to the burden of clinical toxicity. Others have given more importance to the blood flow rate of the dialysate, which should be in excess of $250 \mathrm{ml} / \mathrm{min}$, and that bicarbonate bath optimally be enriched with phosphorus and potassium and dialysis session time should be long (2).

Our results reinforce this trend for more intensified and effective hemodialysis in methanol poisoning (12). We conclude that lowering the threshold level for initiating conventional hemodialysis, especially when the antidote fomepizole is not given for any reason, may benefit the patients with acute methanol poisoning.

\section{Acknowledgements}

None declared.

\section{Financial Disclosure}

None declared.

\section{Funding/Support}

None declared.

\section{References}

1. Jammalamadaka D, Raissi S. Ethylene glycol, methanol and isopropyl alcohol intoxication. Am J Med Sci. 2010;339(3):276-81.

2. Peces R, Fernandez R, Peces C, Gonzalez E, Olivas E, Renjel F, et al. [Effectiveness of pre-emptive hemodialysis with high-flux membranes for the treatment of life-threatening alcohol poisoning]. Nefrologia. 2008;28(4):413-8.

3. Hovda KE, Jacobsen D. Expert opinion: fomepizole may ameliorate the need for hemodialysis in methanol poisoning. Hum Exp Toxicol. 2008;27(7):539-46.

4. Wildenauer R, Kobbe P, Waydhas C. Is the osmole gap a valuable indicator for the need of hemodialysis in severe ethanol intoxication? Technol Health Care. 2010;18(3):203-6.

5. Barceloux DG, Bond GR, Krenzelok EP, Cooper H, Vale JA. American Academy of Clinical Toxicology practice guidelines on the treatment of methanol poisoning. J Toxicol Clin Toxicol. 2002;40(4):415-46

6. Goldfrank LR. Goldfrank's Toxicologic emergencies. 8th ed.: Appleton-Century-Crofts; 2006.

7. Brent J, Wallace KL, Burkhart KK, Phillips SD, Donovan JW. Critical care toxicology: diagnosis and management of the critically poisoned patient. Mosby Philadelphia; 2005.

8. Youssef GM, Hirsch DJ. Validation of a method to predict required dialysis time for cases of methanol and ethylene glycol poisoning. Am J Kidney Dis. 2005;46(3):509-11.

9. Ghannoum M, Haddad HK, Lavergne V, Heinegg J, Jobin J, Halperin ML. Lack of toxic effects of methanol in a patient with HIV Am J Kidney Dis. 2010;55(5):957-61.

10. Burgess E. Prolonged hemodialysis in methanol intoxication. Pharmacotherapy.1992;12(3):238-9.

11. de Arriba G, Torres-Guinea M, Chevarria J, Basterrechea A. [Usefulness of prolonged haemodialysis in acute methanol poisoning]. Nefrologia. 2008;28(6):664-5.

12. Sakuma I, Arakawa M, Hirose Y, Sekiguchi H, Takayama M, Fujisawa M, et al. [Two cases of methanol poisoning with chronological measurements of blood concentrations of methanol, ethanol and formate]. Chudoku Kenkyu. 2010;23:232-7. 